\title{
Semitransparent Polymer Solar Cells Based on Liquid Crystal Reflectors
}

\author{
Shaopeng Yang, Tiening Wang, Xiaohui Zhao, Luo Gu, Qiman Yang, \\ Guang Li, Xiaowei Li, and Guangsheng Fu
}

Hebei Key Laboratory of Optic-Electronic Information Materials, College of Physics Science and Technology, Hebei University, Baoding, Hebei 071002, China

Correspondence should be addressed to Shaopeng Yang; spyang@hbu.edu.cn

Received 19 February 2014; Revised 26 June 2014; Accepted 26 June 2014; Published 9 July 2014

Academic Editor: Mark van Der Auweraer

Copyright (C) 2014 Shaopeng Yang et al. This is an open access article distributed under the Creative Commons Attribution License, which permits unrestricted use, distribution, and reproduction in any medium, provided the original work is properly cited.

The effects of liquid crystal (LC) reflectors on semitransparent polymer solar cells (PSCs) were investigated in this paper. By improving the cathode, we manufactured semitransparent PSCs based on the conventional PSCs. We then incorporated the LC reflector into the semitransparent PSCs, which increased the power conversion efficiency (PCE) from $2.11 \%$ to $2.71 \%$. Subsequently adjusting the concentration and spinning speed of the active layer material changed its thickness. The maximum light absorption for the active layer was obtained using the optimum thickness, and the PCE eventually reached $3.01 \%$. These results provide a reference for selecting LC reflectors that are suitable for different active layer materials to improve the PCE of semitransparent PSCs.

\section{Introduction}

Interest in PSCs has recently increased due to their numerous advantages, such as low fabrication cost, light weight, and flexibility [1-4]. Researchers can improve the PCE of PSCs in many ways. The PSC performance can be improved by modifying the electrodes: for example, a $\mathrm{LiF}, \mathrm{ZnO}$, or poly(ethylene oxide) (PEO) layer can be added between the active layer and cathode to modify the cathode [5-7]. Doping with metal nanoparticles is a method of increasing light absorption that has been used in the manufacturing of solar cells $[8,9]$. Mixed solvents can be used to improve the solar cell performance [10]. The synthesis and use of new materials, such as polysilole(-2,6diyl-alt-5-octylthieno[3,4-c]pyrrole-4,6-dione)(PDTSTPD), poly[[9-(1-octylnonyl)-9H-carbazole-2,7-diyl]-2,5-thiophenediyl-2,1,3-benzothiadiazole-4,7-diyl-2,5-thiophenediyl] (PCDTBT), poly[2,6-(4,4-bis-(2-ethylhexyl)-4H-cyclopenta[2,1-b;3,4-b]dithiophene)-alt-4,7-(2,1,3-benzothiadiazole)] (PCPDTBT), and poly\{[4,8-bis-(2-ethyl-hexyl-thiophene-5yl)-benzo[1,2-b:4,5-b'] dithiophene-2,6-diyl]-alt-[2-(2'-ethylhexanoyl)-thieno[3,4-b]thiophen-4,6-diyl]\}(PBDTTT-C-T), can also improve the PSC efficiency [11-13]. Because conventional solar cells are not generally transparent, they seriously affect the collection of light indoors when installed on building surfaces. Therefore, the transparent solar cells are another important research topic. In 2011, Jan et al. researched semitransparent tandem organic solar cells that contained complementary absorber materials with an average transmission of $24 \%$ in the visible range [14]. In 2012, Kung-Shih Chen et al. researched inverted semitransparent PSCs with a $6 \%$ PCE and 25\% average visible transmittance [15]. Recently, Sharp unveiled a semitransparent siliconbased solar panel that is capable of harnessing energy from the sun while still allowing some light to pass through. These black photovoltaic panels are 1.37 meters by 0.98 meters and only 0.01 meters thick. Each panel is rated at 6.8 percent $/ 95$ watt maximum efficiency.

\section{Experiments and Methods}

In this paper, an LC reflector was used to enhance selective absorption by the PSC. This LC reflector selectively reflects incident light passing through the active layer to be absorbed again. This process increases the photoabsorption with the condition that the reflected light must generally match the absorption spectrum of the active layer [16]. 
Initially, we performed experiments to obtain an absorption spectrum for the active layer materials. Poly(3hexylthiophene) (P3HT) and [6,6]-phenyl C71 butyric acid methyl ester $\left(\mathrm{PC}_{71} \mathrm{BM}\right)$ (purchased from the Lumtec company) were used as the active layer materials. They were dissolved in a chlorobenzene (CB)/chloroform (CF) (Vol/Vol $=3 / 1$ ) mixture with a weight ratio of $1: 1$ and a concentration of $20 \mathrm{mg} / \mathrm{mL}$ [17] and subsequently spin-coated at $1500 \mathrm{rpm}$ onto clean glass to form the active layer, which was annealed at $130^{\circ} \mathrm{C}$ for $20 \mathrm{~min}$. The UV-vis absorption spectrum of the active layer was measured using a spectrophotometer (Hitachi U-4100) as shown in Figure 1.

Figure 1 shows the main absorption band for P3HT: $\mathrm{PC}_{71} \mathrm{BM}$ lies between $480 \mathrm{~nm}$ and $560 \mathrm{~nm}$. To improve the PCE of this PSC, the centre spectral position of the LC reflection band should coincide with the absorption band for the active layer. Two LCs with very special properties, LC242 and LC756, were selected. LC242 is a totipotent nematic LC that can act as a compensation film when used with the polymer. LC756 is a chiral nematic LC that not only acts as a compensation film but also has an optical effect. The dominant reflection wavelengths for mixtures of LC242 and LC756 in different mass ratios are given in Table 1 [18].

A half-wave plate was used as the carrier (purchased from DaHeng), and its dominant reflection wavelength was $523 \mathrm{~nm}$. The miscible LC242 and LC756 forms a thin solid film on the half-wave plate. When the incident light is not polarised, all right-circularly polarised light passes through the LC, while left-circularly polarised light is reflected. The half-wave plate effectively converts the transmitted rightcircularly polarised light into left-circularly polarised light, which is then reflected by the LC reflector. The reflected bandwidth corresponds to the following:

$$
\Delta \lambda=\left(n_{e}-n_{o}\right) p,
$$

where $n_{e}$ and $n_{o}$ are the LC extraordinary and ordinary refractive indices, respectively, and $p$ is the LC pitch. The $\left(n_{e}-n_{o}\right)$ of the half-wave plate used in this paper is $180^{\circ}$. The reflection bandwidth for the LC thin film formed from a mixture of LC242 and LC756 powders in a 95.53:4.47 mass ratio was $80 \mathrm{~nm}$, and the reflection band was centred at $523 \mathrm{~nm}$. The reflection band matched the main absorption spectrum of the $\mathrm{P} 3 \mathrm{HT}: \mathrm{PC}_{71} \mathrm{BM}$ active layer.

We manufactured semitransparent PSCs based on conventional PSCs. Prepatterned ITO-coated glass with a sheet resistance of $12 \Omega$ was used as the substrate and anode electrode. Poly(3,4-ethylenedioxythiophene): poly(styrenesulphonate) (PEDOT:PSS) treated with isopropanol in a volume ratio of $5: 1$ was spin-coated onto the substrate at $3000 \mathrm{rpm}$ for $30 \mathrm{~s}$ [19]. The P3HT: $\mathrm{PC}_{71} \mathrm{BM}$ active layer (the same as mentioned above) was spin-coated at $1500 \mathrm{rpm}$ onto the prepared PEDOT: PSS layer to form a $100 \mathrm{~nm}$ thick active layer. The PSCs were then placed in a drying oven and annealed at $130^{\circ} \mathrm{C}$ for $20 \mathrm{~min}$. The $\mathrm{Al}$ cathode was thermally evaporated in a vacuum chamber through a shadow mask.

Fabricating a semitransparent cathode is key to semitransparent PSCs. Thin metal, conductive polymer, and

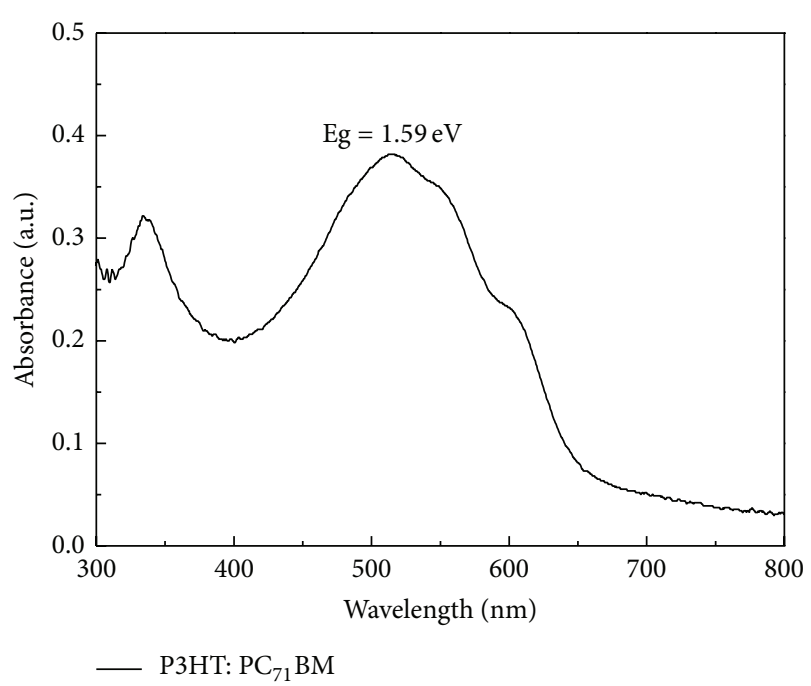

FIGURE 1: UV-vis absorption spectra of P3HT: $\mathrm{PC}_{71} \mathrm{BM}(1: 1)$ thin film $~ 100-n m$ thick, which was formed using a mixed $\mathrm{CB} / \mathrm{CF}$ solution $(\mathrm{Vol} / \mathrm{Vol}=3 / 1)$ as the solvent and annealed at $130^{\circ} \mathrm{C}$ for $20 \mathrm{~min}$.

TABLE 1: The dominant reflection wavelengths associated with different LC242 and LC756 mixtures.

\begin{tabular}{lcc}
\hline LC242 (wt.\%) & LC756 (wt.\%) & $\begin{array}{c}\text { Centre reflection wavelength } \\
\text { (nm) }\end{array}$ \\
\hline 96.89 & 3.11 & 745 \\
96.42 & 3.58 & 682 \\
95.53 & 4.47 & 523 \\
95.24 & 4.76 & 490 \\
94.95 & 5.05 & 457 \\
\hline
\end{tabular}

transparent conductive oxide layers can all be used as semitransparent cathodes [20]. To determine the effect that the Al electrode thickness had on the transparency, we created 20-nm, 30-, 40-, 50-, and 60-nm thick Al electrodes. The transmission spectra for the Al electrodes were measured using a spectrophotometer (Hitachi U-4100). Figure 2 shows that the transmissivity of $20 \mathrm{~nm}, 30 \mathrm{~nm}$, $40 \mathrm{~nm}$, and $50 \mathrm{~nm}$ thick Al electrodes was approximately $24 \%, 14 \%, 8 \%$, and $5 \%$, respectively. The transmittance decreased with increasing $\mathrm{Al}$ electrode thickness. A 60$\mathrm{nm}$ thick Al electrode was largely opaque. Considering the light transmittance requirements, we confirmed that the $\mathrm{Al}$ electrode thickness was approximately $20 \mathrm{~nm}$. However, a 20to $30-\mathrm{nm}$ thick Al electrode is too thin, which drastically influences the semitransparent PSCs' PCE. We selected ZnS as an auxiliary cathode material that not only effectively collects electrons but also has a high light transmittance. The final semitransparent PSC architecture is as follows: Glass/PEDOT : PSS/P3HT : $\mathrm{PC}_{71} \mathrm{BM} / \mathrm{LiF} /(\mathrm{Al} / \mathrm{ZnS})$. The 20$\mathrm{nm} \mathrm{Al}$ and $50-\mathrm{nm} \mathrm{ZnS}$ layers acted as a semitransparent cathode. The active area of the device was $16 \mathrm{~mm}^{2}(4 \mathrm{~mm} \times$ $4 \mathrm{~mm})$. 


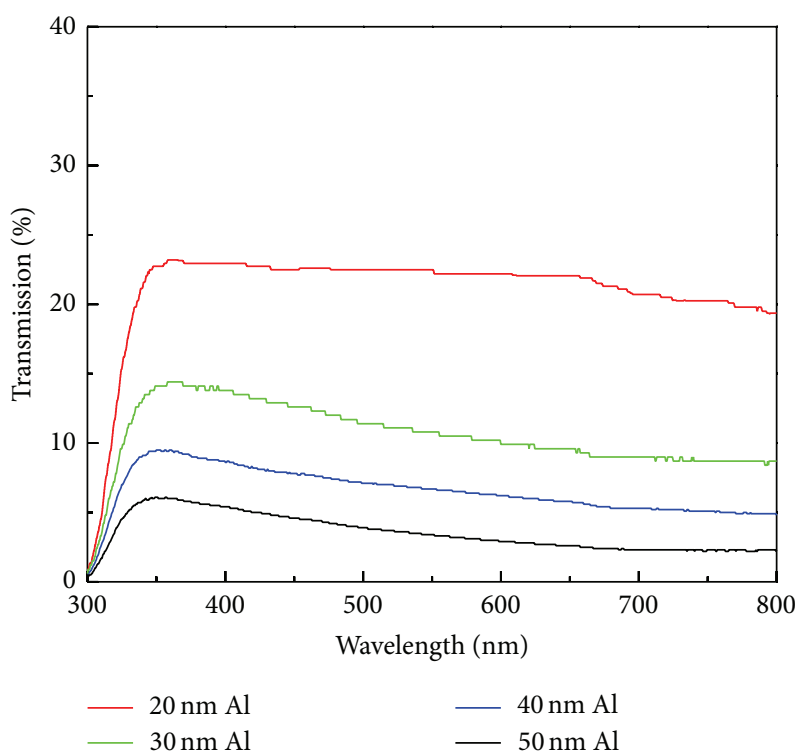

FIgURE 2: The transmission spectrum of the Al electrodes with thicknesses of $20 \mathrm{~nm}, 30 \mathrm{~nm}, 40 \mathrm{~nm}$, and $50 \mathrm{~nm}$.

LC242 and LC756 powders were both mixed in a 95.53 : 4.47 mass ratio in xylene. The LC solution was spincoated onto the half-wave plate and subsequently heated in a drying oven at $85^{\circ} \mathrm{C}$ for $20 \mathrm{~s}$ to enhance the LC alignment. The films were then cross-linked using a UV light source for $10 \mathrm{~min}$ to form a solid layer [21]. The LC film and cell were encapsulated together. A schematic representation of the semitransparent PSC with an LC reflector is shown in Figure 3.

All of the thicknesses were measured using a stylus profiler (Dektak 150). The photocurrent-voltage characteristics were measured using a sun simulator AM $1.5\left(100 \mathrm{~mW} / \mathrm{cm}^{2}\right.$, Japan, San-Ei, ELS 155 (XE)) and Keithley 2400 SourceMeter. The external quantum efficiency (EQE) was measured using the IPCE/QE/spectral response test system (Crown Tech, USA). At room temperature, the photovoltaic properties of the semitransparent polymer solar cells were measured using ITO as the anode, $\mathrm{Al} / \mathrm{ZnS}$ as the cathode, and the light incidences from the anode.

\section{Results and Discussion}

The parameters of semitransparent PSCs both with and without the LC reflector were measured. The active layer was approximately $100 \mathrm{~nm}$ thick. The PSC performance parameters are shown in Table 2(a). The corresponding $J$ $V$ curves were also obtained, as shown in Figure 4(a). For bulk heterojunction solar cells, the open-circuit voltage, $V_{\mathrm{oc}}$, is primarily determined by the highest occupied molecular orbital (HOMO) of the donor and the lowest unoccupied molecular orbital (LUMO) of the receptor [22]. Therefore, the $V_{\mathrm{oc}}$ is almost constant. In contrast, the short circuit density, $J_{\mathrm{sc}}$, is determined by the quantum efficiency or active layer surface morphology. After incorporating the LC reflector, the $J_{\text {sc }}$ increased from $7.54 \mathrm{~mA} / \mathrm{cm}^{2}$ to $9.27 \mathrm{~mA} / \mathrm{cm}^{2}$. Increasing

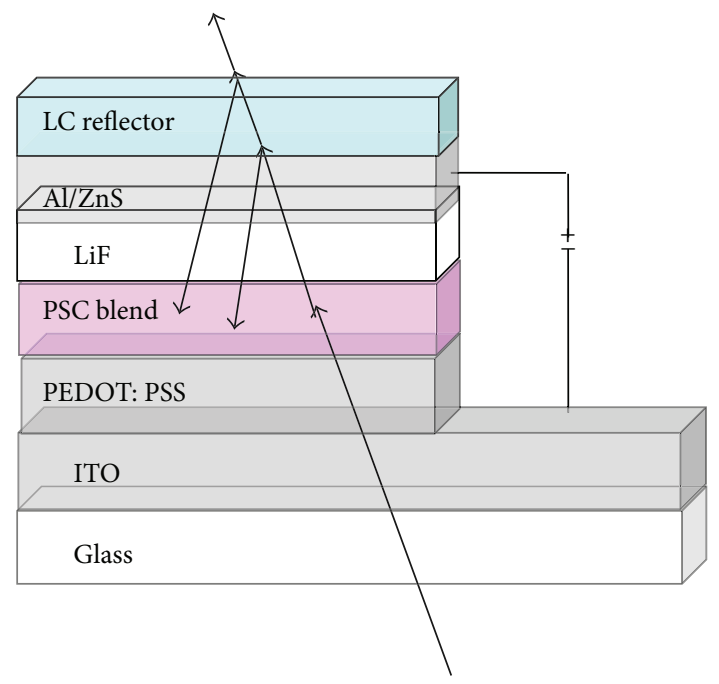

FIGURE 3: Schematic representation of the semitransparent PSC with an $\mathrm{LC}$ reflector.

TABLE 2: Performance parameters for the semitransparent PSCs.

(a) With and without the LC reflector. The active layer thicknesses were both $100 \mathrm{~nm}$

\begin{tabular}{lcccc}
\hline Device & $J_{\mathrm{sc}}\left(\mathrm{mA} / \mathrm{cm}^{2}\right)$ & $V_{\mathrm{oc}}(\mathrm{V})$ & $\mathrm{FF}(\%)$ & $\eta(\%)$ \\
\hline Without LC reflector & 7.54 & 0.53 & 53.2 & 2.11 \\
With LC reflector & 9.27 & 0.53 & 55.6 & 2.71 \\
\hline
\end{tabular}

(b) The semitransparent PSC parameters with the LC reflector; the active layer thicknesses for $\mathrm{A}, \mathrm{B}$, and $\mathrm{C}$ were $150 \mathrm{~nm}, 200 \mathrm{~nm}$, and $250 \mathrm{~nm}$, respectively

\begin{tabular}{lccccc}
\hline Device & $\begin{array}{c}\text { Thickness of } \\
\text { the active } \\
\text { layer }(\mathrm{nm})\end{array}$ & $J_{\mathrm{sc}}\left(\mathrm{mA} / \mathrm{cm}^{2}\right)$ & $V_{\mathrm{oc}}(\mathrm{V})$ & $\mathrm{FF}(\%)$ & $\eta(\%)$ \\
\hline $\mathrm{A}$ & 150 & 10.3 & 0.53 & 53.1 & 2.89 \\
$\mathrm{~B}$ & 200 & 11.2 & 0.53 & 51.0 & 3.01 \\
$\mathrm{C}$ & 250 & 9.2 & 0.53 & 53.5 & 2.59 \\
\hline
\end{tabular}

the photoabsorption increases the PCE from $2.11 \%$ to $2.71 \%$, an improvement of over $28 \%$ relative to the reference solar cell without the LC reflector.

The high efficiency of converting photons into electricity enhanced the PSC performance, which is useful for a power source [23]. In addition, the relationship between the short circuit density, $J_{\mathrm{sc}},\left(\mathrm{mA} / \mathrm{cm}^{2}\right)$ and $\mathrm{EQE}$ corresponds to

$$
J_{\mathrm{sc}}=A_{\text {cell }}^{-1} \int_{0}^{\lambda_{g}} \Phi_{p}(\lambda) \eta_{\mathrm{EQE}}(\lambda) d \lambda,
$$

where $A_{\text {cell }}\left(0.16 \mathrm{~cm}^{2}\right)$ is the solar cell area, $\lambda_{g}(517 \mathrm{~nm})$ is the maximum absorption wavelength, $\Phi_{p}(\lambda)$ is the luminous flux function for standard sunlight, and $\eta_{\mathrm{EQE}}(\lambda)$ is the EQE as a function of the wavelength. Thus, we measure the EQE spectrum for the semitransparent PSCs both with and without the LC reflector. The measured EQE spectra are shown in Figure 5. The EQE of the semitransparent PSCs with an LC reflector increased nearly $10 \%$ from $450 \mathrm{~nm}$ to 


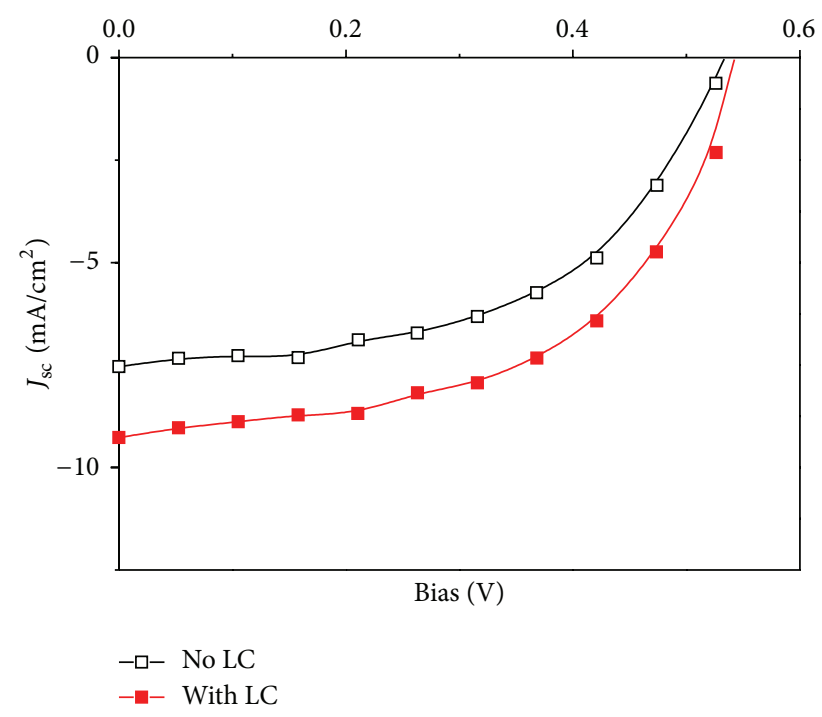

(a)

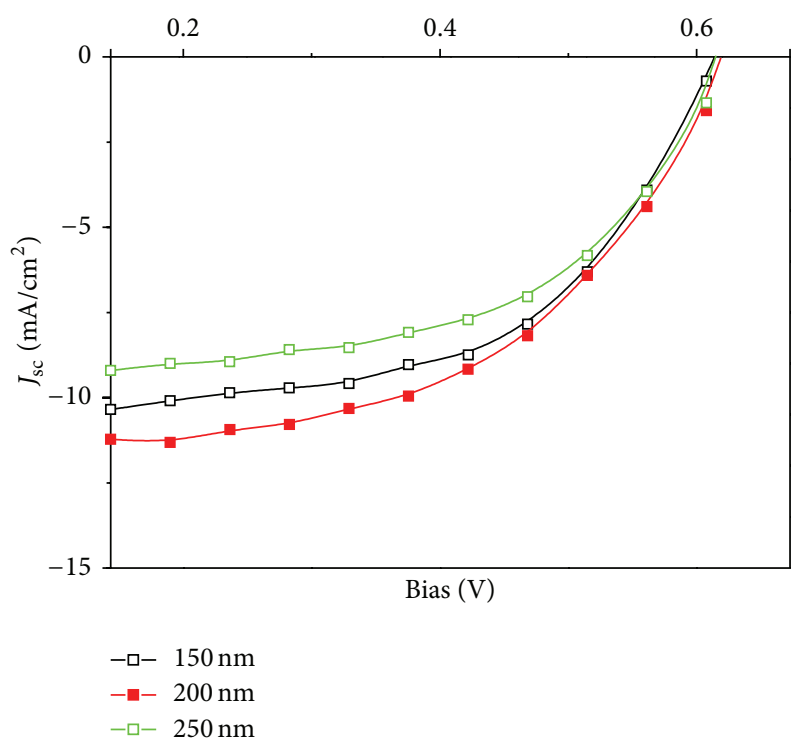

(b)

FIgURE 4: $J$ - $V$ curves for the semitransparent PSCs (a) with and without the LC reflector. The active layer thicknesses were both $100 \mathrm{~nm}$. (b) $J$ - $V$ curves for the semitransparent PSCs with the LC reflector. The thicknesses for active layers A, B, and C were $150 \mathrm{~nm}, 200 \mathrm{~nm}$, and $250 \mathrm{~nm}$, respectively.

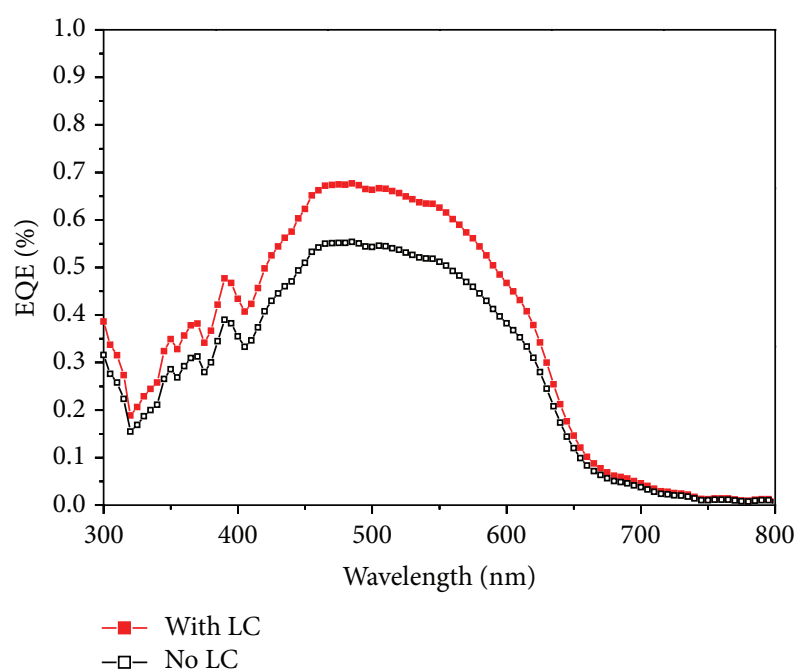

FIGURE 5: The EQE spectra for semitransparent PSCs both with and without the LC reflector; the active layers were both $100 \mathrm{~nm}$ thick.

$550 \mathrm{~nm}$, as shown in Figure 5, which is in response to the reflected band from the LC reflector. For the solar cells, the number of generated electrons depends on the number of photons near the absorption peak. Adding the LC reflector increases the number of electrons generated; more than doing so increases the total number of incident photons. Thus, the semitransparent PSCs with the LC reflector have a higher EQE.

Although the best conventional PSCs are approximately $100 \mathrm{~nm}$ thick, perhaps more light reflected by the LC reflector should be absorbed by the active layer again. We should determine the best active layer thickness for PSCs using an $\mathrm{LC}$ reflector. We then fabricated three more semitransparent PSCs with LC reflectors, named A, B, and C, using the method described above. A mixed $\mathrm{CB} / \mathrm{CF}$ solution (Vol/Vol $=3 / 1$ ) was still used as the solvent; however, the active layer concentrations for $\mathrm{A}, \mathrm{B}$, and $\mathrm{C}$ were $25 \mathrm{mg} / \mathrm{mL}, 30 \mathrm{mg} / \mathrm{mL}$, and $35 \mathrm{mg} / \mathrm{mL}$, respectively. Active layer thicknesses of $150 \mathrm{~nm}, 200 \mathrm{~nm}$, and $250 \mathrm{~nm}$ were obtained for A, B, and C, respectively. The performance parameters for PSCs with LC reflectors are shown in Table 2(b), and the corresponding $J$ $V$ curves were obtained as shown in Figure 4(b). Table 2(b) directly verified the preliminary assumption that the initial thickness $(100 \mathrm{~nm})$ is insufficient. A concentration of $30 \mathrm{mg} / \mathrm{mL}$ and thickness of $200 \mathrm{~nm}$ are best for PSCs with LC reflectors. Thicknesses above or below $200 \mathrm{~nm}$ adversely affect the semitransparent PSCs.

\section{Conclusions}

In summary, we manufactured a semitransparent PSC based on conventional PSCs by improving the cathode. The active layer thickness was still approximately $100 \mathrm{~nm}$. We then incorporate the LC reflectors into the semitransparent PSCs, and the incident light that passes through the active layer is selectively reflected and absorbed by the active layer again. The PCE increased from $2.11 \%$ to $2.71 \%$, an improvement of over $28 \%$ compared with a reference solar cell without an LC reflector. More light reflected by the LC reflector should be absorbed by the active layer thin film again compared to the conventional PSCs. Therefore, we researched the optimum thickness for the semitransparent PSC active layer when using an LC reflector. When the active layer thickness is approximately $200 \mathrm{~nm}$, the $J_{\mathrm{sc}}$ increased from $9.27 \mathrm{~mA} / \mathrm{cm}^{2}$ 
to $11.2 \mathrm{~mA} / \mathrm{cm}^{2}$. The PCE of the semitransparent PSC with an LC reflector reached 3.01\%.

\section{Conflict of Interests}

The authors declare that there is no conflict of interests regarding the publication of this paper.

\section{Acknowledgments}

The authors are grateful to the Natural Science Foundation of Hebei Province (Grant nos. F2010000306, F2012201089, and A2011201008) and Hebei Province Department of Education Fund ( $\mathrm{ZH} 2011205$ ) for funding this work.

\section{References}

[1] W. Cai, X. Gong, and Y. Cao, "Polymer solar cells: recent development and possible routes for improvement in the performance," Solar Energy Materials and Solar Cells, vol. 94, no. 2, pp. 114-127, 2010.

[2] C. J. Brabec, N. S. Sariciftci, and J. C. Hummelen, "Plastic solar cells," Advanced Functional Materials, vol. 11, no. 1, pp. 15-26, 2001.

[3] P. Peumans, A. Yakimov, and S. R. Forrest, "Small molecular weight organic thin-film photodetectors and solar cells," Journal of Applied Physics, vol. 93, no. 7, pp. 3693-3723, 2003.

[4] J. J. M. Halls and R. H. Friend, "The photovoltaic effect in a poly(p-phenylenevinylene)/perylene heterojunction," Synthetic Metals, vol. 85, no. 1-3, pp. 1307-1308, 1997.

[5] C. J. Brabec, S. E. Shaheen, C. Winder, N. S. Sariciftci, and P. Denk, "Effect of LiF/metal electrodes on the performance of plastic solar cells," Applied Physics Letters, vol. 80, no. 7, pp. 1288-1290, 2002.

[6] S. H. Park, H. J. Kim, M. Cho et al., "The effect of $\mathrm{ZnO}$ surface conditions on the electronic structure of the $\mathrm{ZnO} / \mathrm{CuPc}$ interface," Applied Physics Letters, vol. 98, no. 8, Article ID 082111, 2011.

[7] F. Zhang, M. Ceder, and O. Inganäs, "Enhancing the photovoltage of polymer solar cells by using a modified cathode," Advanced Materials, vol. 19, no. 14, pp. 1835-1838, 2007.

[8] S. Yang, M. Yao, T. Jiang et al., "Effect of aluminium nanoparticles on the performance of bulk heterojunction organic solar cells," Chinese Physics Letters, vol. 29, no. 9, Article ID 098402, 2012.

[9] F. Xie, W. C. H. Choy, C. C. D. Wang, W. E. I. Sha, and D. D. S. Fung, "Improving the efficiency of polymer solar cells by incorporating gold nanoparticles into all polymer layers," Applied Physics Letters, vol. 99, no. 15, Article ID 153304, 2011.

[10] F.-L. Zhang, K. G. Jespersen, C. Björström et al., "Influence of solvent mixing on the morphology and performance of solar cells based on polyfluorene copolymer/fullerene blends," Advanced Functional Materials, vol. 16, no. 5, pp. 667-674, 2006.

[11] X. Zhao, H. Tang, D. Yang et al., "Effect of molecular weight and processing additive on the performance of low bandgap polymer solar cells," Chinese Journal of Chemistry, vol. 30, no. 9, pp. 2052-2058, 2012.

[12] L. J. Huo, S. Q. Zhang, X. Guo, F. Xu, Y. F. Li, and J. H. Hou, "Replacing alkoxy groups with alkylthienyl groups: a feasible approach to improve the properties of photovoltaic polymers,"
Angewandte Chemie - International Edition, vol. 50, no. 41, pp. 9697-9702, 2011.

[13] J. Hou, H. Chen, S. Zhang et al., "Synthesis of a low band gap polymer and its application in highly efficient polymer solar cells," Journal of the American Chemical Society, vol. 131, no. 43, pp. 15586-15587, 2009.

[14] M. Jan, M. Torben, L. Karl et al., "Highly efficient semitransparent tandem organic solar cells with complementary absorber materials," Applied Physics Letters, vol. 99, no. 4, Article ID 043301, 2011.

[15] K.-S. Chen, J.-F. Salinas, H.-L. Yip, L. Huo, J. Hou, and A. K.-Y. Jen, "Semi-transparent polymer solar cells with 6\% PCE, 25\% average visible transmittance and a color rendering index close to 100 for power generating window applications," Energy \& Environmental Science, vol. 5, no. 11, pp. 9551-9557, 2012.

[16] Y. Galagan, M. G. Debije, and P. W. M. Blom, "Semitransparent organic solar cells with organic wavelength dependent reflectors," Applied Physics Letters, vol. 98, no. 4, Article ID 043302, 2011.

[17] S. Yang, N. Li, G. Li, J. Shi, X. Li, and G. Fu, "Effect of mixed solvents on P3HT:PCBM based solar cell," Acta Physica Sinica, vol. 62, no. 1, Article ID 014702, pp. 2836-2841, 2013.

[18] BASF, "Paliocolor LC242 and LC756, performance chemicals," Technical Information, BASF, Ludwigshafen, Germany, 2002.

[19] B. Peng, X. Guo, C. Cui, Y. Zou, C. Pan, and Y. Li, "Performance improvement of polymer solar cells by using a solvent-treated poly(3,4-ethylenedioxythiophene):poly(styrenesulfonate) buffer layer," Applied Physics Letters, vol. 98, no. 24, Article ID 243308, 2011.

[20] G. M. Ng, C. Vijila, W. P. Goh, and F.-R. Zhu, "Translucent polymer solar cells," ECST, vol. 18, no. 1, pp. 869-874, 2009.

[21] D. J. Broer, G. N. Mol, J. A. M. M. van Haaren, and J. Lub, "Photo-induced diffusion in polymerizing chiral-nematic media," Advanced Materials, vol. 11, no. 7, pp. 573-578, 1999.

[22] Y. Hayashi, H. Sakuragi, T. Soga, I. Alexandrou, and G. A. J. Amaratunga, "Bulk heterojunction solar cells based on two kinds of organic polymers and fullerene derivative," Colloids and Surfaces A: Physicochemical and Engineering Aspects, vol. 313-314, pp. 422-425, 2008.

[23] J. D. Servaites, M. A. Ratner, and T. J. Marks, "Practical efficiency limits in organic photovoltaic cells: functional dependence of fill factor and external quantum efficiency," Applied Physics Letters, vol. 95, no. 16, Article ID 163302, 2009. 

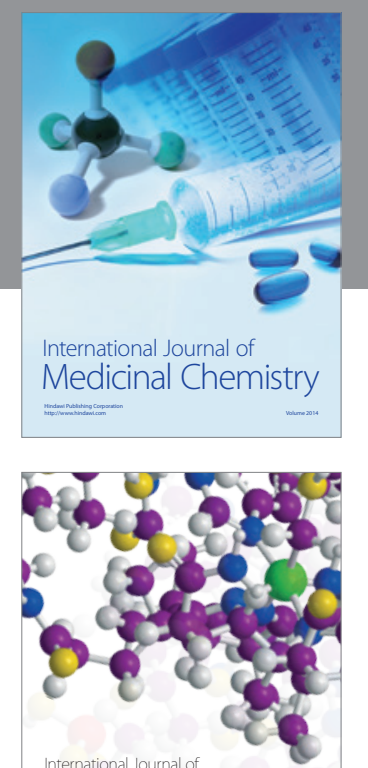

\section{Carbohydrate} Chemistry

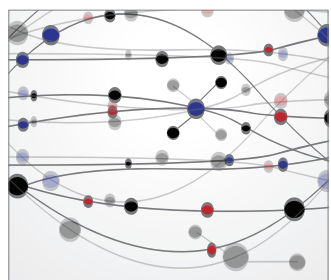

The Scientific World Journal
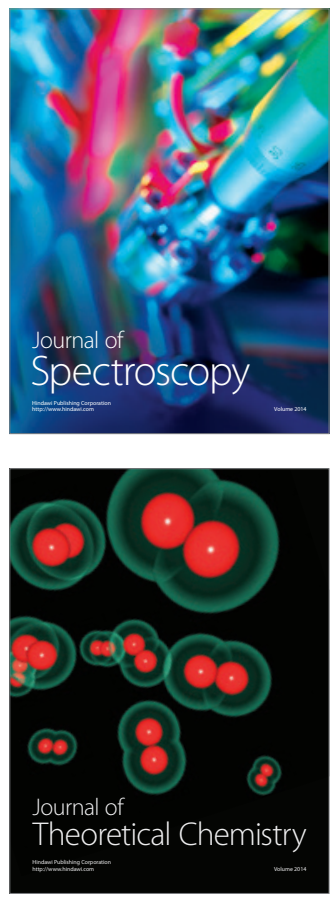
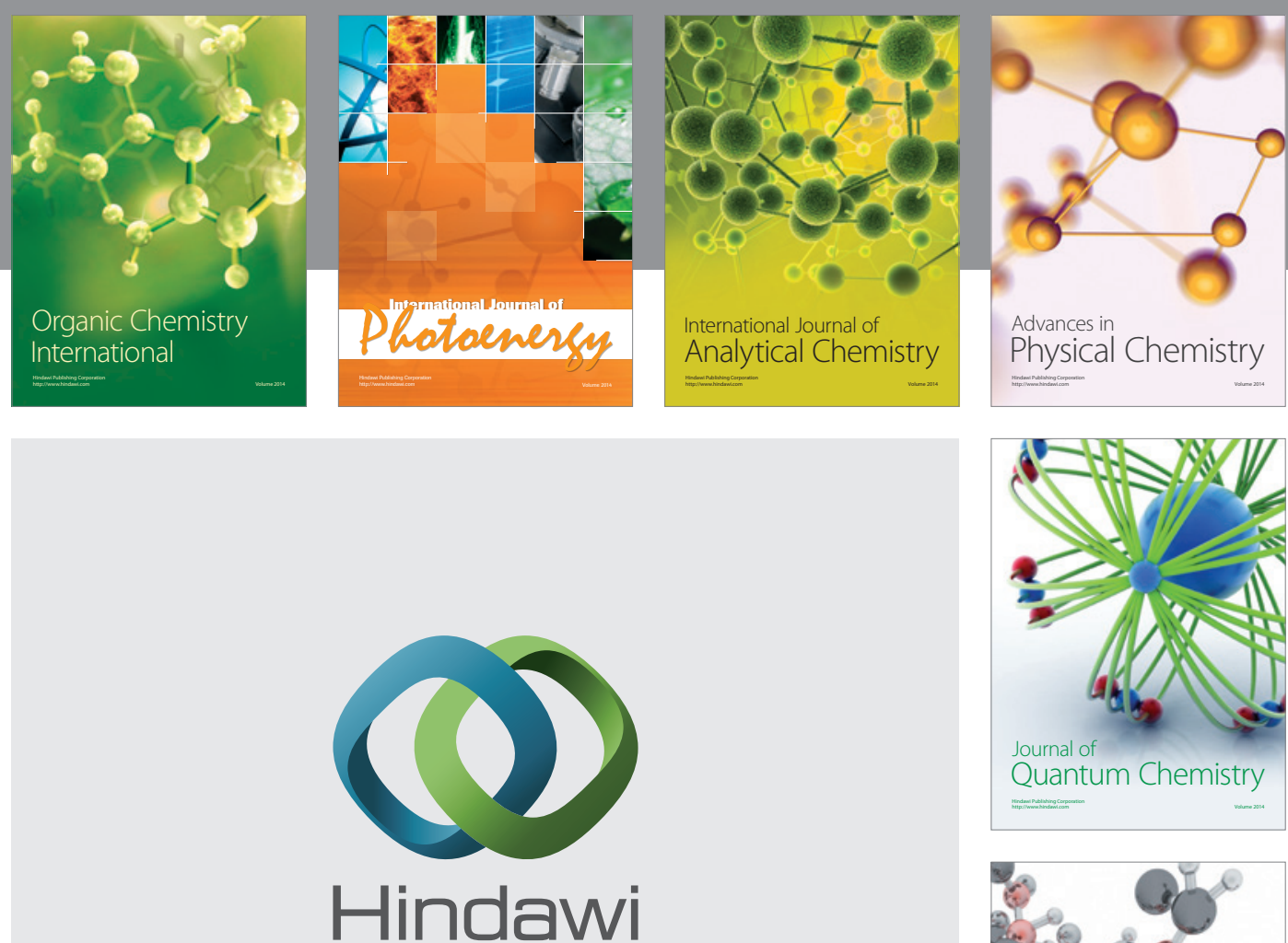

Submit your manuscripts at

http://www.hindawi.com

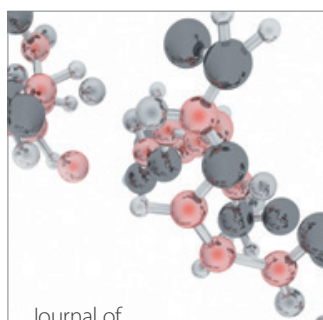

Analytical Methods

in Chemistry

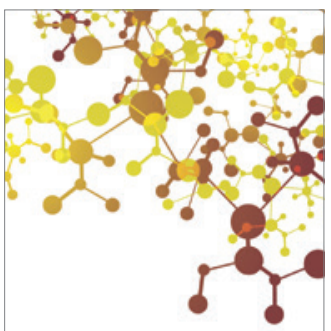

Journal of

Applied Chemistry

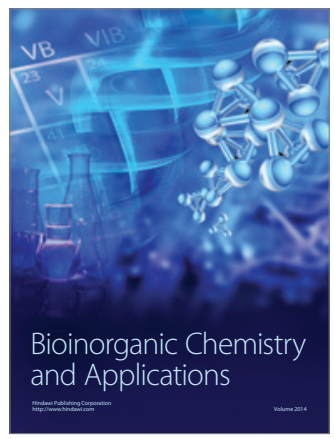

Inorganic Chemistry
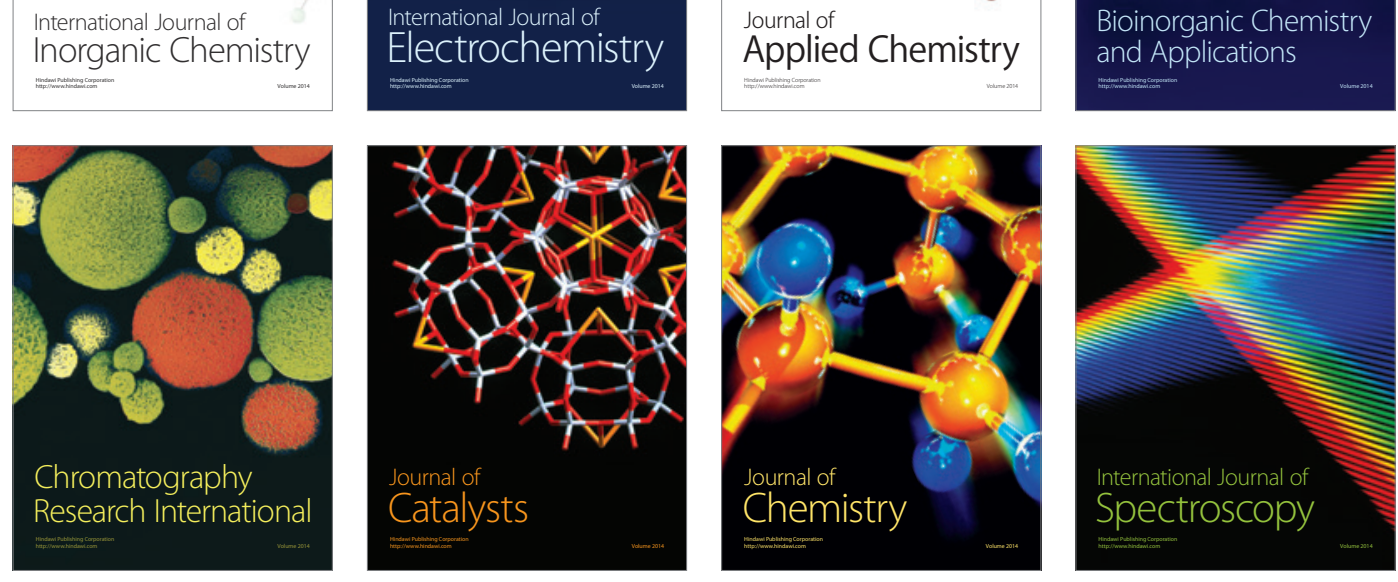